\title{
On the robust effects of technology shocks on hours worked and output.
}

\author{
Fabio Canova * \\ ICREA-UPF, AMeN, CEPR \\ David Lopez-Salido \\ Claudio Michelacci \\ Board of Governors and Bank of Spain \\ CEMFI
}

November 2006

\begin{abstract}
We analyze the effects of neutral and investment-specific technology shocks on hours worked and output. Low frequency movements in hours are captured in a variety of ways. Hours robustly fall in response to neutral shocks and robustly increase in response to investment specific shocks. The percentage of the variance of hours (output) explained by neutral shocks is small (large); the opposite is true for investment specific shocks. News shocks and other shocks are uncorrelated with the estimated neutral and investment specific shocks.
\end{abstract}

JEL classification: E00, J60, O33.

Key words: Technology disturbances, structural VARs, low frequency movements, news shocks.

\footnotetext{
${ }^{*}$ We would like to thank Thijs Van Rens and Albert Marcet for comments and suggestions, Neville Francis, Susantu Basu, Sergio Rebelo and Franck Portier for kindly sharing their data.
} 


\section{Introduction}

There has been a renewed interest in examining the effects of technology shocks on either total or per-capita hours worked following the work of Gali (1999), Uhlig (2004), Dedola and Neri (2004), Christiano et. al. (2005), Francis and Ramey (2005), Chari, et. al. (2005) among others. This interest is typically motivated by the fact that the dynamics of hours differ if such a disturbance occurs in a basic RBC model (hours increase) or in a basic sticky-price model (hours decrease).

Unfortunately, the empirical evidence on the relationship between technology shocks and hours worked is mixed. Four main reasons contribute to make the task of applied investigators complicated: first, technology shocks are difficult to identify and only their long run implications are considered robust to measurement and specification errors; second, different types of technological disturbances may potentially have different implications for fluctuations in hours worked; third, the choice of price deflators may be crucial in assessing the effects of technological disturbances; fourth, the response of hours worked appears to depend on a number of auxiliary assumptions, including the treatment of the low frequency movements in hours, the length of the VAR - theoretical models used to guide the interpretation of the results may not be approximable with finite order VARs - and the horizon at which the identifying restrictions are imposed.

Regarding the low frequency movements in hours, two contrasting arguments are typically made. If we condition the analysis on the models one uses to interpret the results as, for example, Christiano et. al. (2005), Uhlig (2004), Dedola and Neri (2004) do, per-capita hours should enter the VAR in level since both basic RBC and basic New-Keynesian models produce stationary fluctuations in this variable, even when the technology is drifting in a non-stationary fashion. If we condition the analysis on the statistical properties of the data and follow a classical statistical approach, as e.g. Gali (1999), and Francis and Ramey (2005) do, the VAR should include hours in differences. However, unit root tests are unlikely to be conclusive with the available sample sizes and, as one can see from figure 1, per-capita hours display a non-linear U-shaped trend which makes the outcome of these tests dubious. Since both approaches are potentially subject to specification errors, it is not clear which strategy to follow. The alternative suggested by Fernald (2004) - to break the sample in pieces - is economically more appealing but statistically equally problematic since small sample biases may entirely drive the results.

The issue of the length of VAR has been brought back to the attention of applied researchers by the recent contributions of Giordani (2004) and Chari et. al. (2005), who show that a subset of the variables generated by standard models may have a solution which is not always representable with a finite order VAR. FernandezVillaverde et. al. (2005), who provide conditions to construct valid VAR approxi- 
mations. This issue is important in our context because estimated VARs typically include only a small subset of the potentially interesting variables and because the lag length may be too short to capture the implied dynamics when the true DGP is an VARMA with large MA roots.
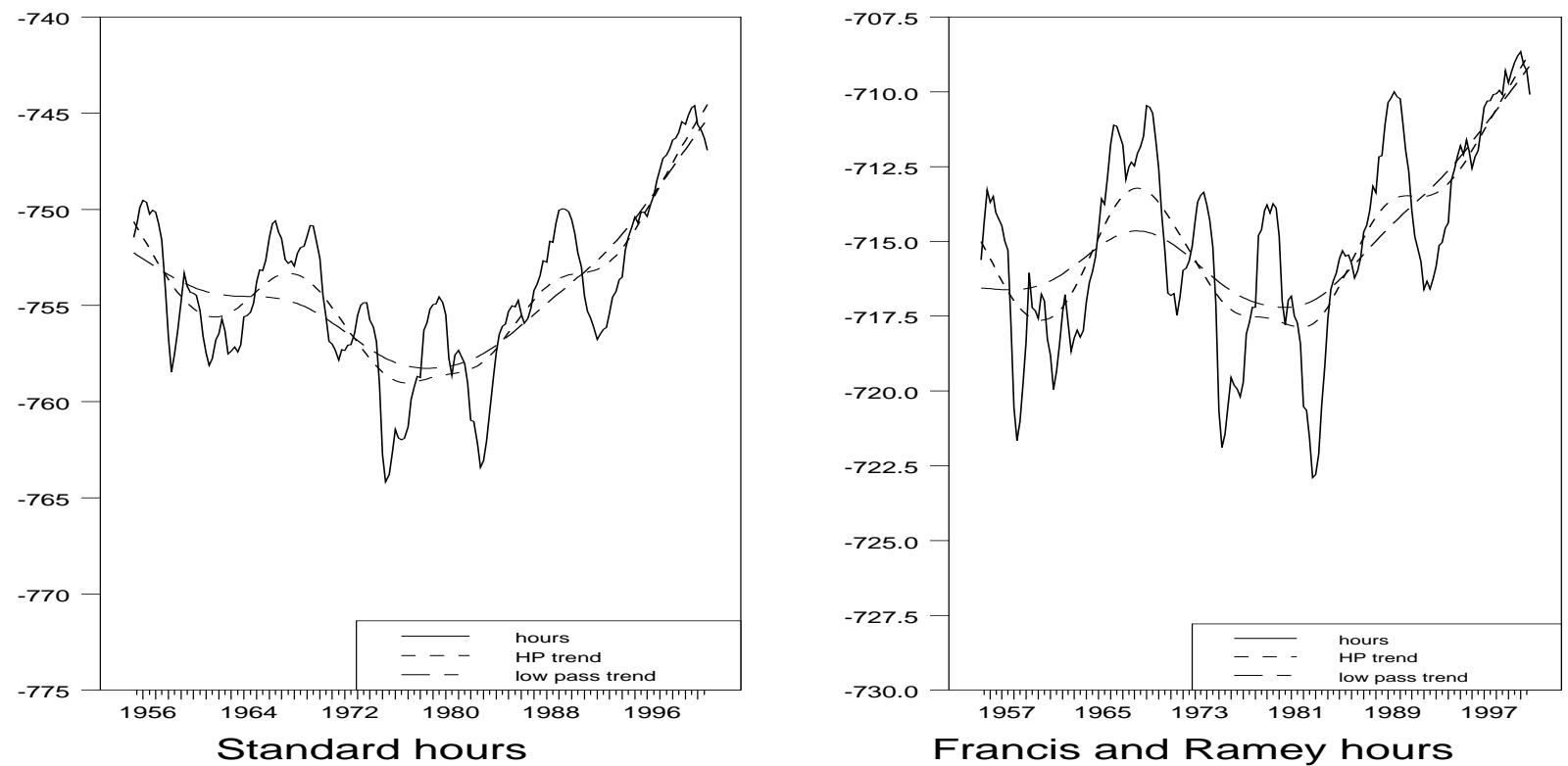

Figure 1: Per-capita hours, $\operatorname{HP}(\lambda=6400)$ and low pass trends.

Canova et. al. (2006) have argued that, in measuring the effects of technological disturbances on hours worked, it matters whether the CPI or the GDP deflator is used. Theoretically, CPI and GDP deflators differ if the economy is open to foreign trade. Empirically, it is unclear which choice is made. Hence, it is difficult to gauge whether the results hinge on this assumption or not.

Moreover, the fact that different primitive shocks may have similar long run implications as technology shocks, that long run restrictions are weak in the sense of Faust and Leeper (1997), and that the available samples are too short to credibly impose such restrictions (see Erceg, et al. (2005)) has prompted researchers to search for alternative identification strategies (see e.g. Uhlig (2004), Dedola and Neri (2004)). Finally, the evidence of Beaudry and Portier (2005) - that technology shocks are essentially the same as news shocks - is puzzling for this line of research. 
In this paper we revisit the issue of what are the effects of technology on hours worked by directly dealing both with the presence of low frequency movements in hours and the potential misspecifications created by the use of VARs with a limited number of variables and a finite number of lags. In addition, we examine the robustness of the conclusions to alternative identification approaches and different measures for the price of investment goods; and we separately analyze the dynamics induced by neutral and investment specific technology shocks. We show that once one takes care of low frequency movements in hours worked in any reasonable manner, all the other pieces of the puzzle become irrelevant: hours robustly fall in response to neutral technology shocks, and the fall occurs primarily at nonrecessionary times, and robustly increase in response to investment specific shocks.

The contribution of neutral shocks to the fluctuations in hours worked is small, while the contribution of investment specific shocks is substantial. Interestingly, the relative importance of the two shocks for output fluctuations is reversed: neutral shocks explain about twice as much of the forecast error variance of output than investment specific shocks at all horizons. Our estimated neutral shock has peaks and troughs in correspondence of NBER peaks and throughs, while the investment specific shock fails to display these features. We also show that our technology shocks do not stand in for any other likely sources of disturbances, that they are unrelated to news shocks, and that are substantially different from the technology shocks one would extract from accounting exercises. Finally, our analysis indicates that a large portion of hours and output fluctuations can be attributed to a disturbance specific to the labor market.

The evidence we uncover is hard to reconcile with simple flexible price and sticky price models of transmission, popular in the literature. Canova, et. al. (2006) show that the responses of unemployment and of labor market flows to neutral shocks are also hard to reconcile with extensions of these models which include serach frictions and sicky wages and provide a Schumpeterian model of creative destruction that can account for both the sign and the relative magnitude of hours and output responses described here and the labor market facts they uncover.

The rest of the paper is organized as follows. Section 2 critically summarizes the existing evidence. Section 3 provides new evidence when low frequency movements in hours worked are accounted for in a variety of ways. Section 4 shows that our results are robust to a number of changes in the auxiliary assumptions. Section 5 examines the properties of the estimated shocks. Section 6 concludes. 


\section{The existing evidence}

We summarize existing evidence and the current stae of the debate in the context of a three equation VAR model composed of labor productivity, the price of investment, both measured in consumption units, and per-capita hours, which is the minimum sized system required to distinguish between neutral and investment specific shocks. Since such a small model is liable to specification errors, we later show how to check for potential omitted variables. The sample runs from 1955:1 to 2000:4. We present results when all three variables enter the VAR in first difference (the difference system) and when the first two enter in first difference and per-capita hours are in logs (the level system). Investment specific shocks are identified by the requirement that they are the sole source of movements in the price of investment in the long run while neutral shocks can affect both labor productivity the price of investment in the long run. Fisher (2006) has shown how to derive these restrictions from two basic equations embedded in models of both neoclassical and New-Keynesian orientations: a production function with unit root disturbances and a capital accumulation equation where the price of investment is stochastic and displays a unit root. We use 12 lags of each variable; stochastically restrict their decay toward zero as lag length increases.

The first row of figures 2 reproduces what is more or less known in the literature: in the level system, per-capita hours positively respond to a neutral shock, the maximum response is delayed by about 5 quarters and the instantaneous impact is insignificant. In the difference system, per-capita hours fall for up to 4 quarters and settle to their long run level from above, but all the responses are insignificant.

The sign difference in the point estimates across specifications is often attributed to low frequency movements in hours worked and the fact that, when these movements are not accounted for, they distort the dynamics in the level system. The right panel of figure 1 confirms the results obtained with the level system are probably spurious. However, such a pattern does not necessarily imply the existence of non-stationarity dynamics, as it is commonly assumed (see e.g. Gali (2005)) there could be stationary cycles with long but finite periodicity - resulting in standard overdifferencing problems. In addition, a difference specification, emphasizing high frequency hours variability, may magnify the importance of measurement errors therefore producing standard error bands which are large relative to those obtained with the level specification (as it is the case in figure 2). Hence, both the difference and the level specifications are probably misspecified and it is difficult to draw conclusions on the relative credibility of the results they produce.

One alternative way to take care of low frequency movements is split the sample in pieces. We follow the literature and choose 1973:2 as a break point (see Greenwood and Yorokoglu (1997) and Fernald (2004) for a justification of this choice). 

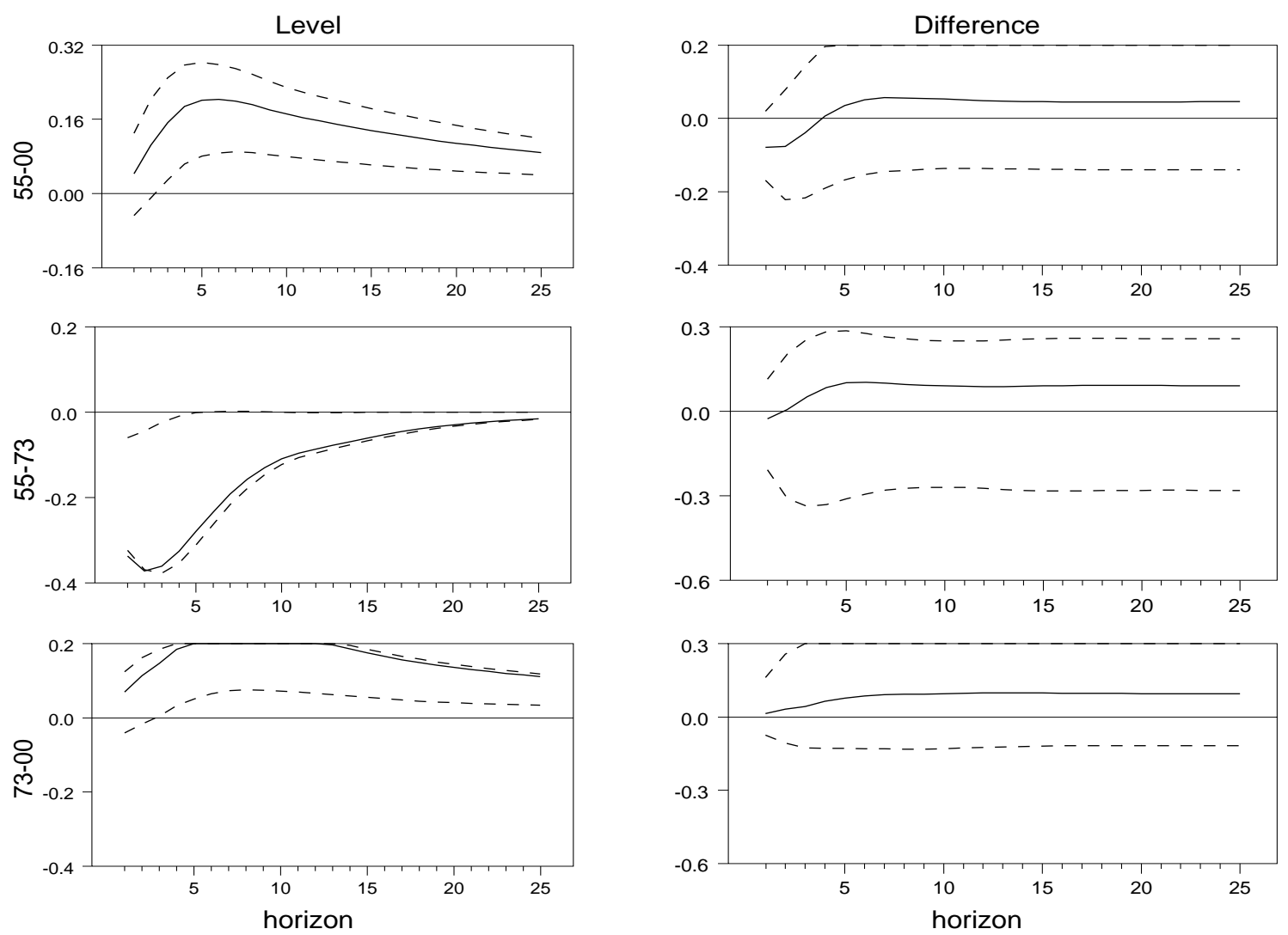

Figure 2: Responses of hours, neutral shocks.

The second and the third rows of figure 2 report the responses of per-capita hours in two subsamples for the two specifications. The results appear to have considerably changed. For the sample 1955-1973, hours instantaneously fall in both specifications: in the level system significantly so; in the differences system responses continue to be insignificant. The point estimate of the response of hours in the level specification is persistently negative and significantly so up to 4 quarters, while for the difference specification, the point estimate turns positive after just one quarter, but remain insignificant at all horizons. For the 1973-2000 sample, hours instantaneously increase in both specifications. In the level system, responses are significant only after 4 quarters. In the difference specification responses are positive at all horizons, albeit insignificant. Simple inspection of figure 1 indicates that the trend in the hours series may have changed once again somewhere in 1990s. We have 
therefore repeated estimation using data up to 1997:1 for the second subsample: the responses of hours to neutral shocks remain positive in both specifications and significant only in the level system after about 4 quarters.

Neutral technology shocks are not the only possible source of long run fluctuations in real variables. For example, Uhlig (2004) indicates that tax shocks may have roughly the same effects as neutral shocks and Fisher (2006) suggests that investment specific shocks could be an important source of technological disturbances.
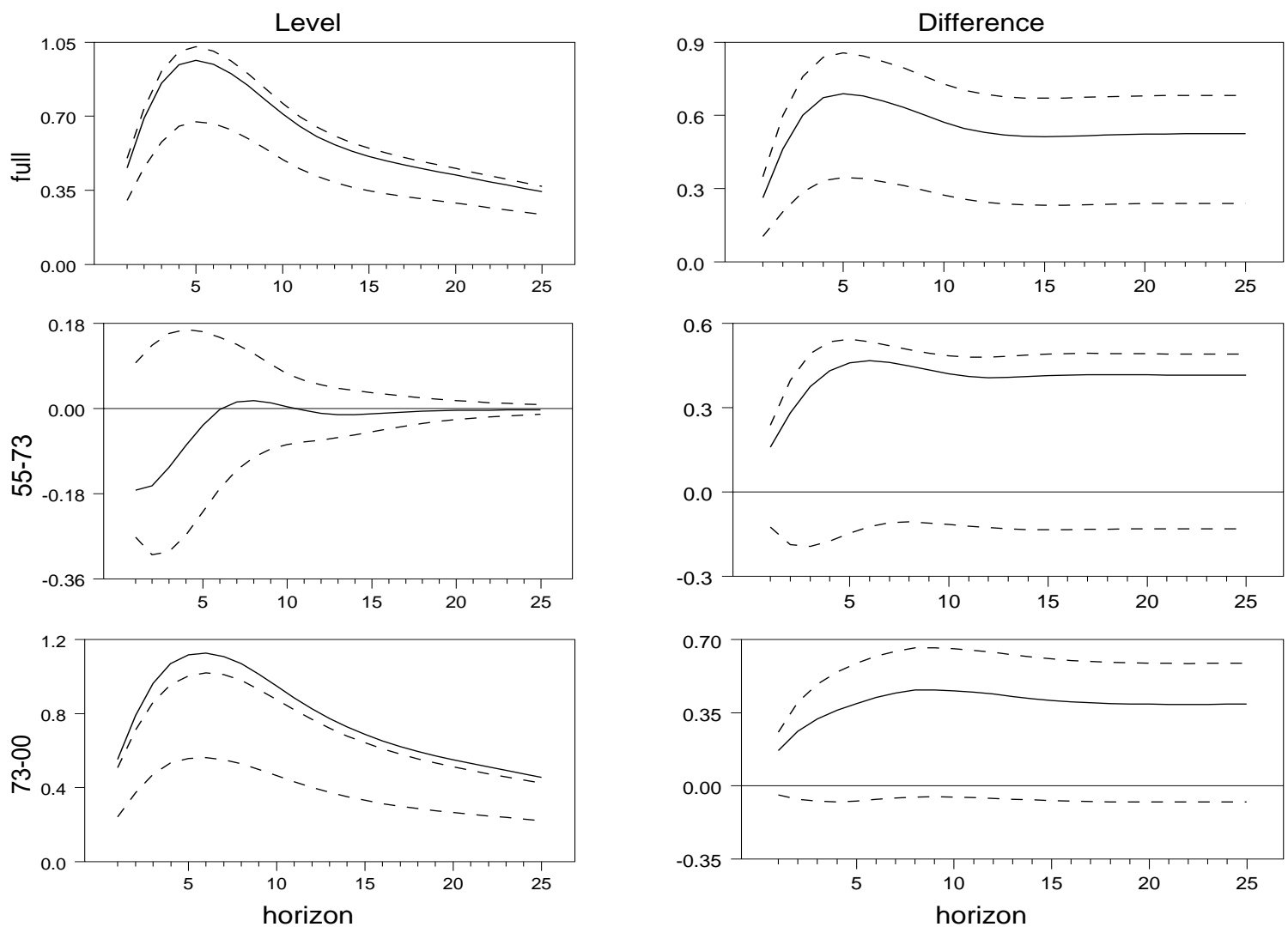

Figure 3: Responses of hours, investment specific shocks.

Figure 3 presents per-capita hours responses to investment specific shocks for the full sample and the same two subsamples analyzed in figure 2 for the level and the difference system. For the full sample, the two specifications agree: hours responses display a hump shaped pattern; the increase is instantaneously significant; 
and the magnitude of the effect is roughly similar. When we split the sample results differ across specifications: hours fall in the 1955-1973 sample and increase in the 1973-2000 sample in the level system but in the first sample estimates are insignificant. For the difference system, the instantaneous point estimate is positive in both subsamples, but none of the responses is significant.

While neutral disturbances account for less than 2 percent of the variability of hours worked at horizons ranging from 8 to 24 quarters in both specifications, investment specific shocks appear to be a more important source of cyclical variations in per-capita hours. In fact, they explain 16-21 percent of the variability of hours in the difference specification and 49-65 percent in the level specification at horizons ranging from 8 to 24 quarters. These percentages are roughly unchanged when teh sample is split in two.

How does one interpret this evidence? Typically, the instability found in the level system is thought to reflect improper treatments of low frequency movements in percapita hours. But should one trust subsample evidence? Probably not, because to take care of one potential misspecification problem (low frequency movements), an approach which splits the sample in pieces introduces potentially large small sample biases. Small sample biases make estimates unreliable for many reasons. First, point estimates are less informative than otherwise: this is evident comparing standard error bands across rows in figures 2 and 3. Second, identifying long run restrictions imposed in a system estimated over a small sample are likely to induce serious distortions in the structural estimates (see Erceg, et. al. (2005)). Third, small sample biases may interact in an unpredictable way with measurement and aggregation errors, making subsample evidence uninterpretable. Hence, neither assuming unit roots nor splitting the sample in piece seems the best way to account for the low frequency movements that per-capita hours display.

\section{Dealing with low frequency variations}

The cyclical components that result from taking the difference between the actual series and, e.g., the two trend estimates we have presented in figure 1, are reasonably stable over time. Therefore, splitting the sample and tracing out the dynamics separately in each of them is inefficient, as there appears to be little changes in the cyclical patterns of hours. To take care of low frequency movements in per-capita hours we have considered several options. In the first case, the intercept in the hour equation is deterministically broken at 1973:2 and 1997:1 (the dummy specification); in the second case the intercept is allowed to be a deterministic function of time (up to a third order polynomial); in the third case we prefilter the hours series with a one-sided low-pass filter, which takes away cycles with periodicities higher than 52 
quarters ${ }^{1}$; and in the fourth one the intercept drifts stochastically and potentially continuously over time. In this latter case, we specify an autoregressive meanreverting law of motion and use the Kalman filter to recursively estimate it. Note that with all specifications, the biases induced by the use of long run restrictions are considerably reduced, since the full sample of quarterly data is now employed to project estimated VAR coefficients infinitely far into the future.
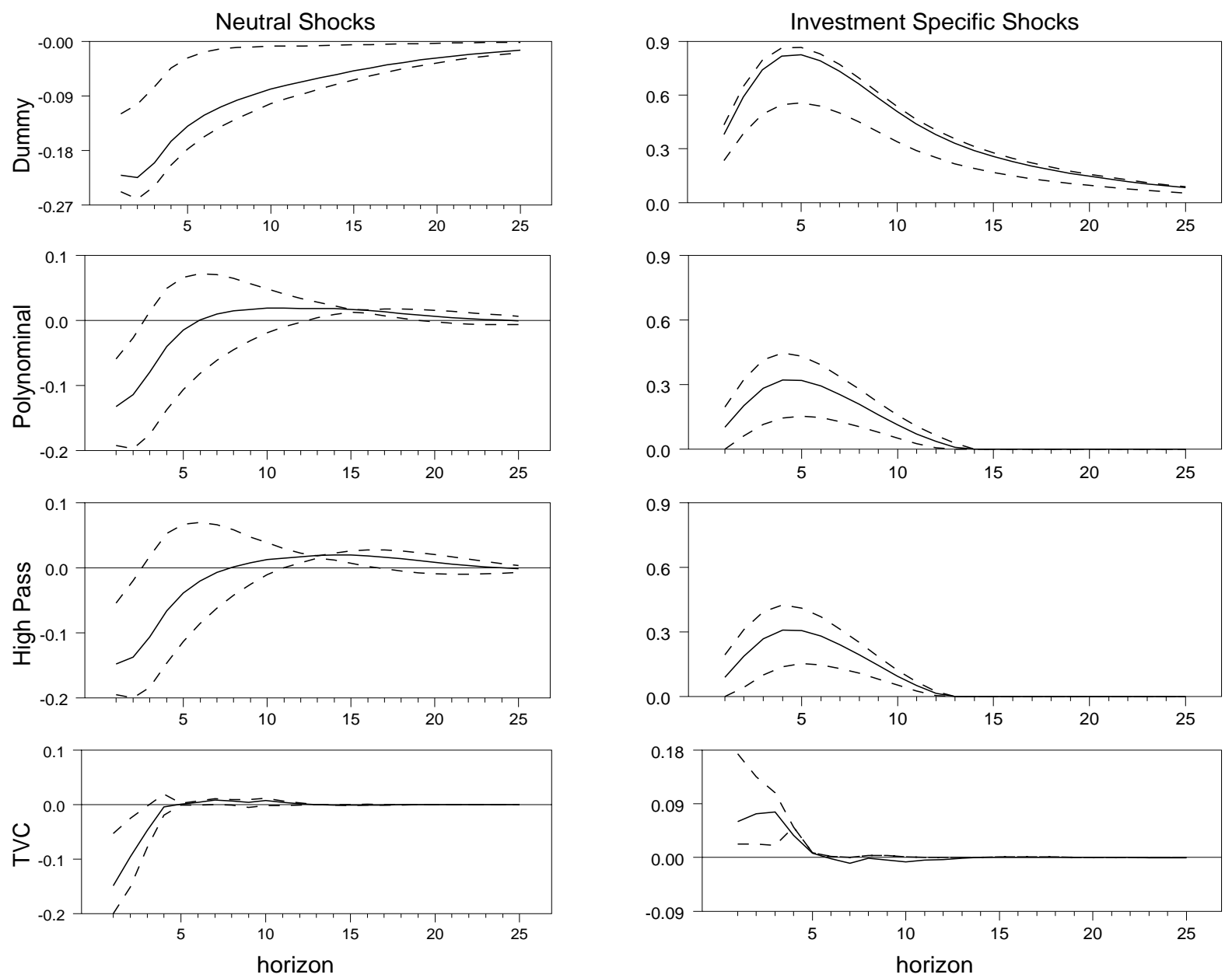

Figure 4: Responses of hours, various detrending, 1955-2000

\footnotetext{
${ }^{1}$ The filter is one minus the low pass filter plotted in figure 1.
} 
We present the response of per-capita hours in these specifications in figure 4: the first column refers to neutral shocks and the second to investment specific shocks. The results are very robust: per-capita hours fall in response to neutral shocks and increase in response to investment specific shocks and the instantaneous response is always significant. Depending on the exact specification, the fall in response to neutral shocks is either persistent (first row) or temporary (next three rows). Nevertheless, in no case a hump results after 4-5 quarters.

The percentage of the variance of per-capita hours explained by the shocks is similar in the four specifications: neutral disturbances have negligible effects on per-capita hours at horizons varying between 8 and 24 quarters (the upper 95th percentile of the distribution is always below 10 percent) while investment specific shocks explain between 30-50 percent of the variance of hours at these horizons (2030 percent with the continuously varying intercept specification). Interestingly, for output fluctuations the opposite is true: neutral shocks explain on average about 35 percent of output fluctuations and investment specific shocks only about 18 percent of output fluctuations, regardless of the horizon (see figure 5 for the dummy specification).
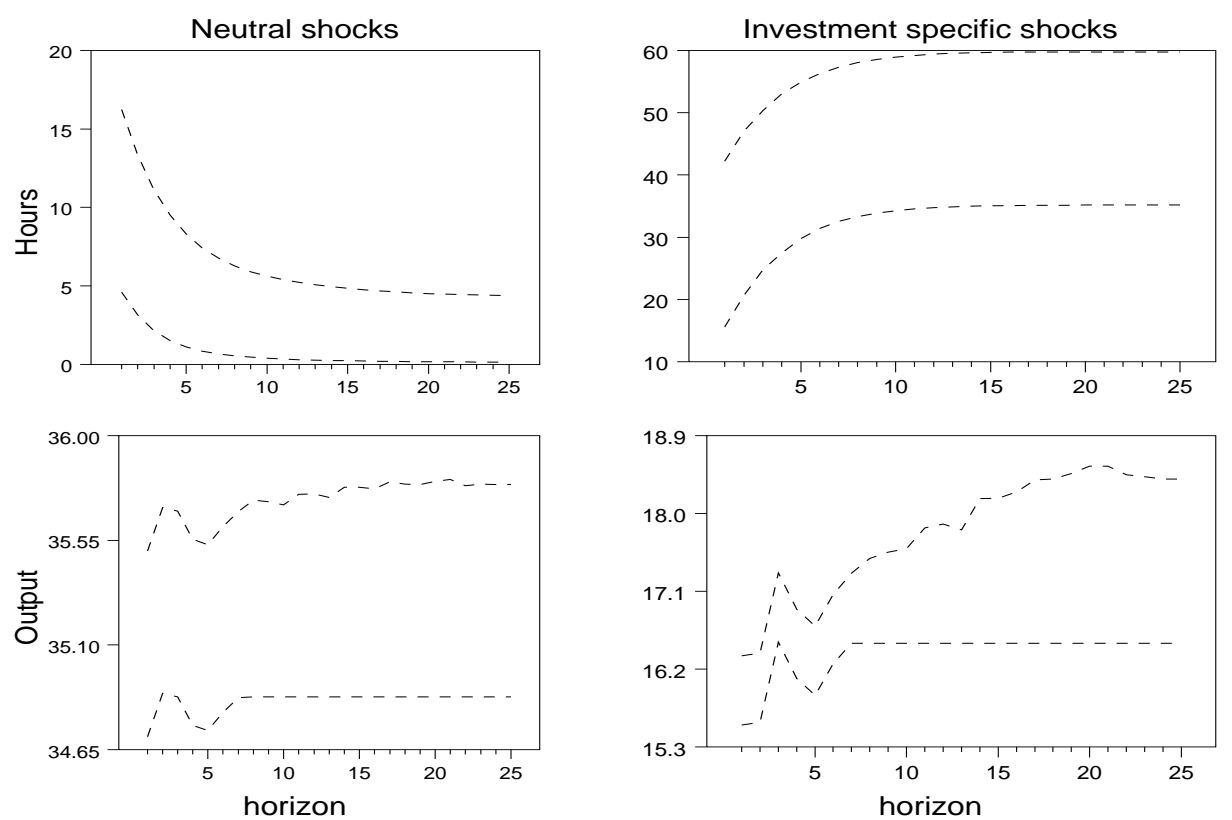

Figure 5: Variance decomposition, dummy specification, 1955-2000, 90 percent bands 
Altig, et. al. (2005) have estimated the effects of neutral and investment specific shocks on a number of US variables using the identification approach but a slightly different sample (1959:1-2001:4). They report that the contribution of both shocks to per-capita hours and output volatility at business cycle frequencies is roughly the same (about 15 percent). However, their numbers are percentages obtained on average at the business cycle frequencies of the spectrum, while here we report percentages obtained on average at business cycle horizons. Hence, the larger explanatory power that neutral shocks have for output and that investment specific shocks have for per-capita hours comes from frequencies other than strict business cycles ones.
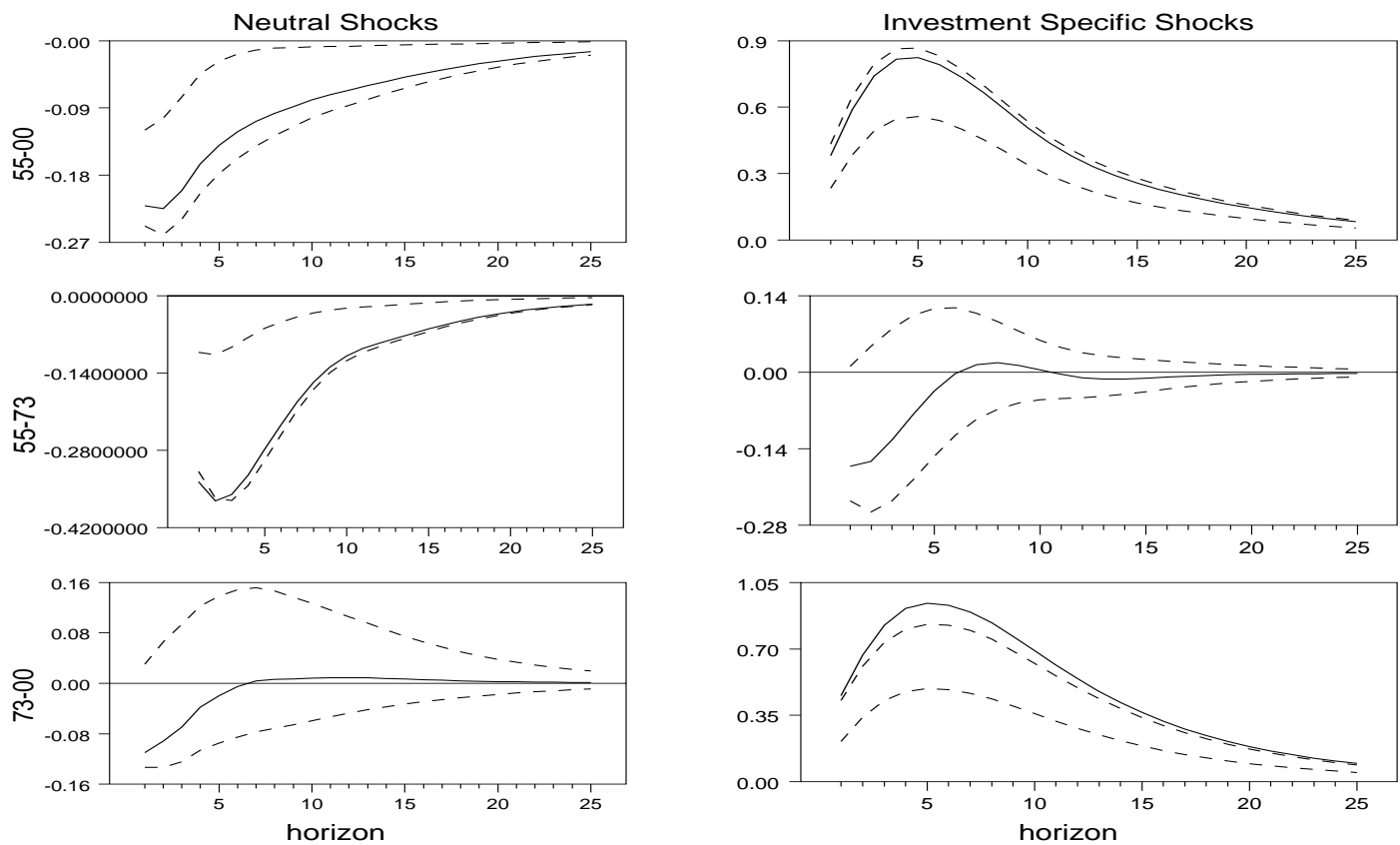

Figure 6: Responses of hours, different samples, dummy specification

One question of interest is whether there are time instabilities in the response of hours to technology shocks with any of the specifications employed in figure 4 . The subsample evidence presented in figures 2 and 3 was unintepretable because of the potential interactions between small sample biases and improper treatment of low frequency movements. Clearly, small sample biases will always be present in short subsamples. Nevertheless, to the extent that low frequency movements are now properly taken into account, subsample analysis should be more informative. 
Figure 6 reports for the dummy specification. The responses of per-capita hours to neutral shocks are now negative in both subsamples; they are significant and somewhat persistent in the 1955-1973 sample but always insignificant in the 19732000 sample. The responses to investment specific shocks are positive and significant in the 1973-2000 sample and are similar to those obtained in the full sample. For the 1955-73 sample, the responses are insignificant at all horizons. Interestingly, estimates of the response to investment specific shocks are comparable to those present in figure 3. Hence, while low frequency movements in hours matter for the dynamics in response to neutral shocks, they are unimportant in deciding the sign and the significance of the responses to investment specific shocks.

Are these conclusions robust? There are many dimensions along which robustness could be checked, making the combination of systems to be estimated quite large. We divide our analysis into two parts. First, we study the robustness of the results to the choice of variables and their measurement. Second, we check whether outcomes are sensitive to the statistical assumptions we have made. As it will be clear, our conclusions are quite robust.

\section{Robustness}

To start with we analyze the robustness of the results to the measurement of real variables. In the systems we have run, labor productivity and the price of investment are measured in consumption units. However, it is easy to show that if foreign goods enter the consumption basket, long run movements in labor productivity can also be driven by external shocks. Since the output basket is less prone to such problems, we have repeated the exercise measuring either labor productivity or both the labor productivity and the price of investments with the output deflator. The first row of figure 7 shows that the sign and the shape of both responses is unchanged.

Second, we have repeated our exercises using the recently constructed hours series of Francis and Ramey (2006). This series displays less low frequency movements than the standard one but, it is still not void of them (see right panel of figure 1). Therefore, it can be used to check if our treatment of low frequency movements is appropriate. The results obtained running the systems with the new series are in the second row of figure 7: clearly none of the conclusions is altered.

Third, we add four more years of data and repeat the exercise using a newly constructed price of investment series. The third row of figure 7 shows that the response of hours to neutral shocks becomes less significant but overall no major changes are visible. 

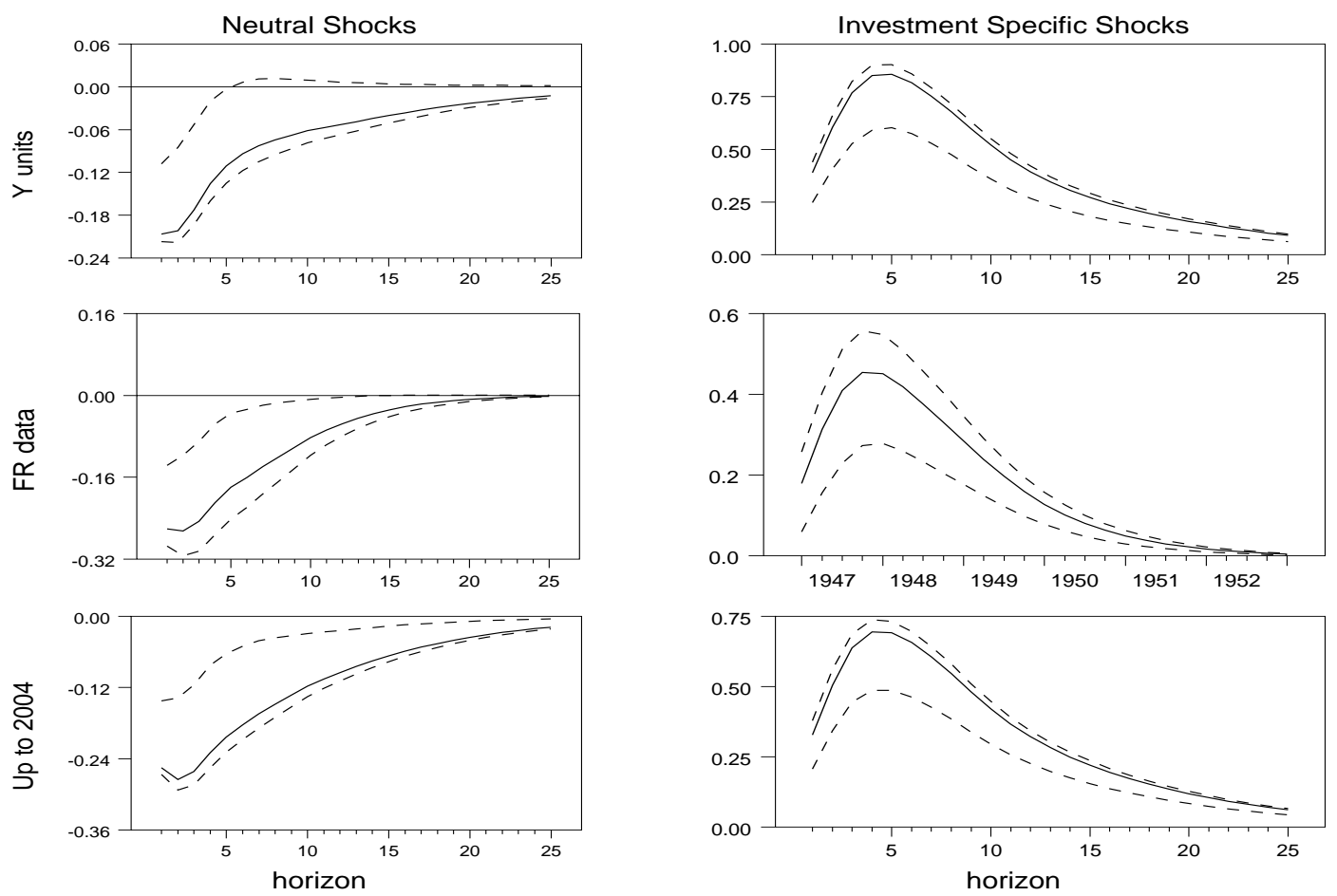

Figure 7: Responses of per-capita hours, Alternative measurements, Dummy specification, 1955-2000

Fourth, while we have allowed long enough lags in each estimated specification, it is always possible that omitted variables play a role in the results. For example, Evans (1992) showed that Solow residuals are correlated with a number of policy variables, therefore making responses to Solow residuals shocks uninterpretable. To check for this possibility we have correlated our two estimated technology shocks with variables which a large class of general equilibrium models driven by neutral and investment specific shocks suggests as being jointly generated with the data we have used. Figure 8, which reports the correlations of consumption to output, investment to output, and inflation with the estimated structural shocks up to 4 leads and 4 lags and the upper and lower limits of an asymptotic 95 percent confidence band for the dummy specification, suggests that this is not the case. In none of the estimated system we find that omitted variables are strongly correlated with the estimated structural shocks: the maximum point estimate of these cross-correlation is -0.20 and occurs with the dummy specification.

We have also correlated our estimated technology shocks with oil prices, federal funds futures and tax shocks. These are constructed as the residuals of univariate 
regressions of each of the three variables on two lags each. The effective tax series is taken from the Congressional Budget Office and is transformed into quarterly frequency using an interpolation routine. The correlations are all small and never exceed 0.11 in absolute value for cross correlations up to 4 lags and 4 leads. Therefore, our technological disturbances do not appear to stand-in for other sources of technological and non-technological disturbances either.
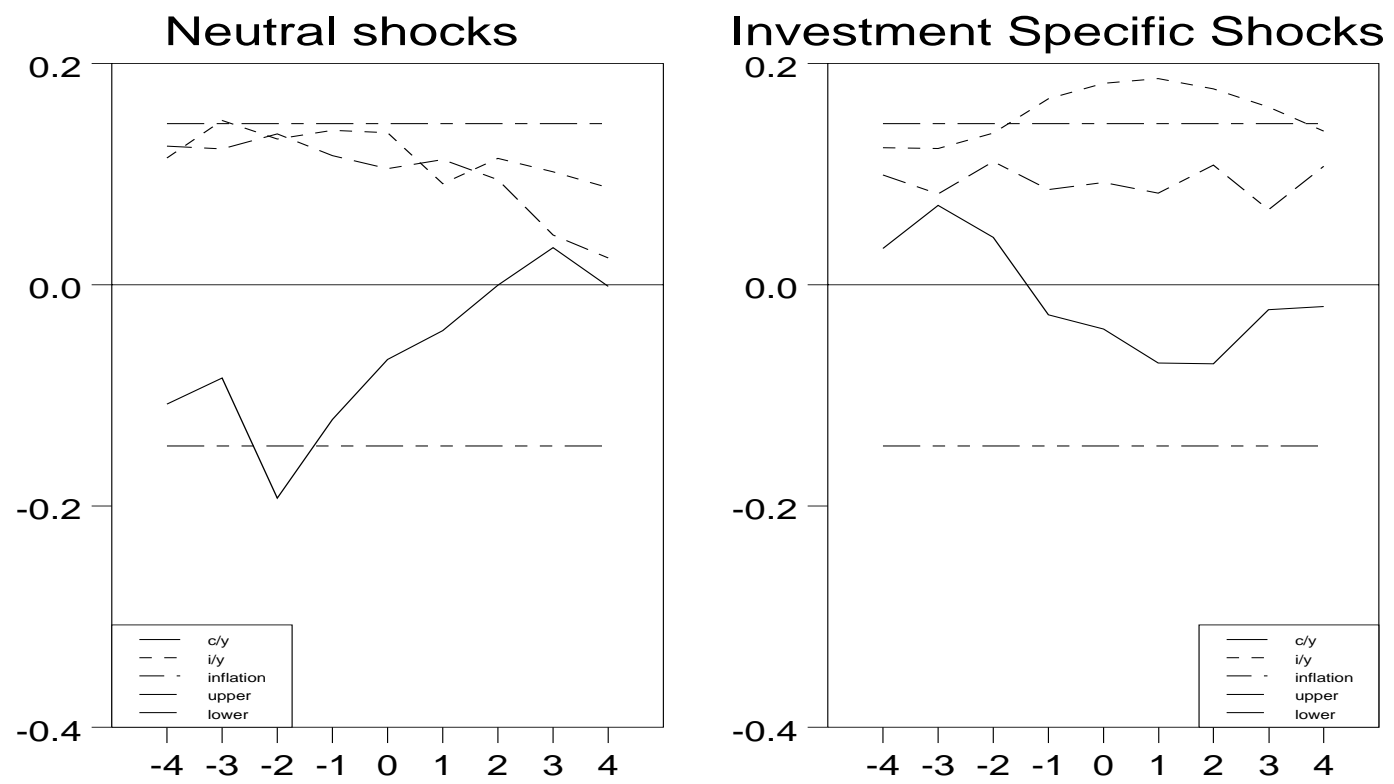

Figure 8: Cross correlation structural shocks-omitted variables, dummy specification, 1955-2000

Another way to examine the potential effects of omitted variables is to check the robustness of the results to changes in the lag length. To the extent that omitted variables result in VAR residuals with MA components, adding lags to the model should help to eliminate this problem (as shown in Chari, et. al. (2005)). We report median estimates and standard error bands for the contemporaneous response of per-capita hours worked to the two shocks in figure 9 for the dummy specification. It is clear that the sign of the responses is very robust to the choice of lag length. Interestingly, when a short lag length is used, the contemporaneous response to neutral shocks becomes more strongly negative. 

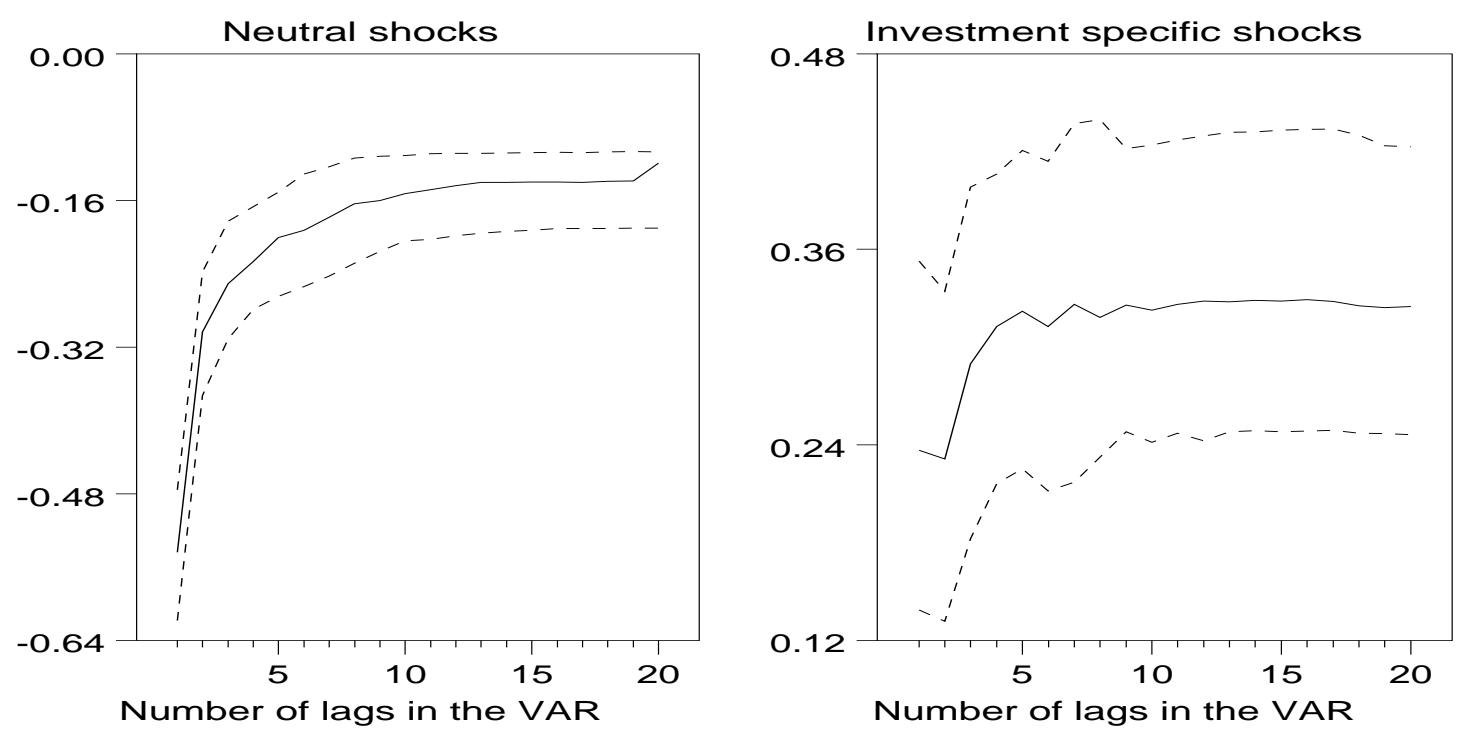

Figure 9: Contemporaneous response of hours, dummy specification, 1955-2000

Fifth, we modified the way response bands are computed. OLS estimates of VAR coefficients are typically biased downward in small samples. If these are used
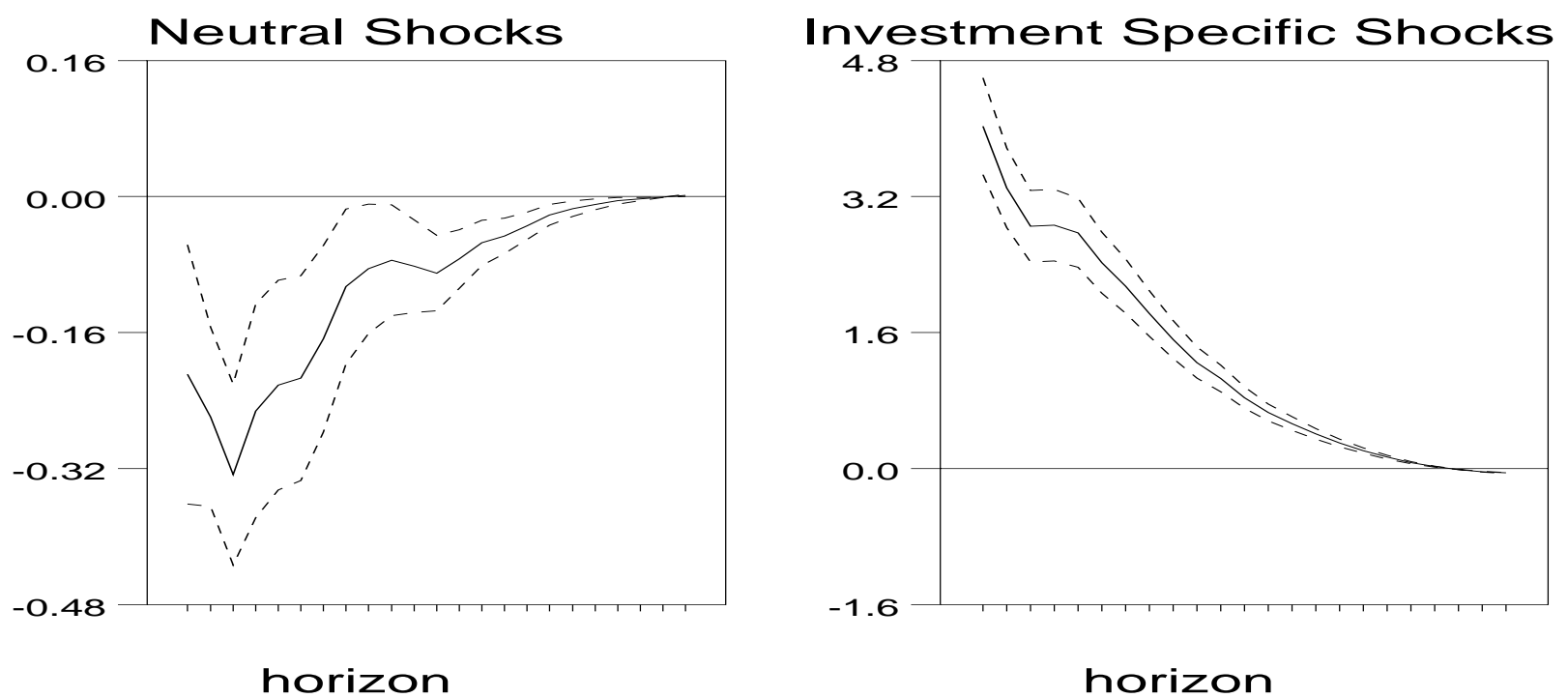

Figure 10: Correcting OLS bias, Dummy specification, 1955-2000 
to construct bootstrap samples, they produce standard error for impulse responses which are wrongly centered and possibly biased. While our sample is not necessarily short, systems with a large number of lags are subject to the same problems. We have therefore computed standard error bands using the bootstrap-after-the-bootstrap approach of Kilian (1998) for each of the systems we have presented in figure 4. None of our conclusions change. For illustration purposes, we present responses in the dummy specification in figure 10. Apart from the fact that bands are tighter and that the hump in response to investment specific shock has disappeared, no other qualitative difference is visible.
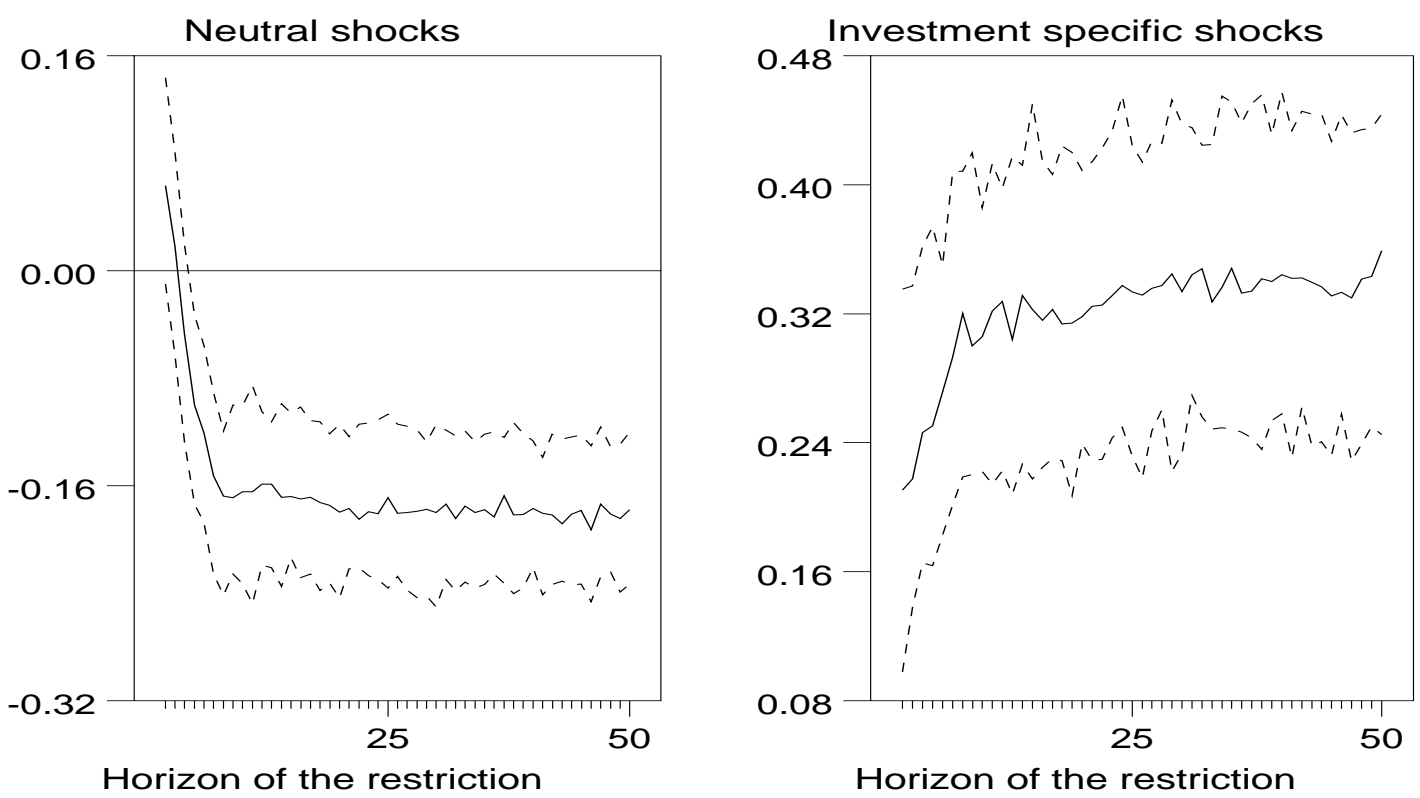

Figure 11: Contemporaneous response of hours, dummy specification, 1955-2000

Sixth, we have altered the identification restrictions. Uhlig (2004) has forcefully argued that disturbances other than neutral technology shocks may have long run effects on labor productivity and that, in theory, there is no horizon at which neutral shocks fully account for the variability of labor productivity. This means that the neutral shocks we have extracted may not be structural. Beaudry and Portier (2005) found empirical evidence consistent with this interpretation: neutral technology shocks obtained in this way are highly correlated with "information" shocks extracted using short run restrictions and a bivariate system with total factor productivity and stock prices. To study whether this is a problem, we have imposed 
the restriction that investment specific shocks are the sole source of fluctuations in the price of investment and that neutral and investment specific shocks are the sole source of fluctuations in labor productivity at horizons varying $k=1, \ldots 50$. We report in figure 11 the impact response of hours worked for the dummy specification. It is clear that the sign of the response is robust to the horizon at which the restriction is imposed, it is significant in all the specifications, except for the neutral shock at horizons shorter than 3 quarters.

Long run restrictions are vacuous if the series they constrain are stationary around some deterministic trend or simply nearly integrated. When this is the case one needs to devise alternative restrictions to identify the two shocks of interest. Dedola and Neri (2004), for example, assume stationarity of VAR variables and use sign restrictions derived from an RBC model to identify technology shocks. Do the responses of hours to the two technology shocks dependent on whether we condition on the price of investment and labor productivity having or not having a unit root and, in the latter case, identifying shocks using sign restrictions?

The sign restrictions we choose are simple and are likely to be shared by a number of models with different micro-fundations: we require that in response to a neutral shocks, productivity responses are contemporaneously non-negative while the response of the (relative) price of investment is contemporaneously positive; and that in response to an investment specific shock, productivity responses are contemporaneously positive and price of investment contemporaneously negative. We are extremely parsimonious in the number of restrictions we employ: only the contemporaneous effects are constrained; lagged effects are totally unrestricted.
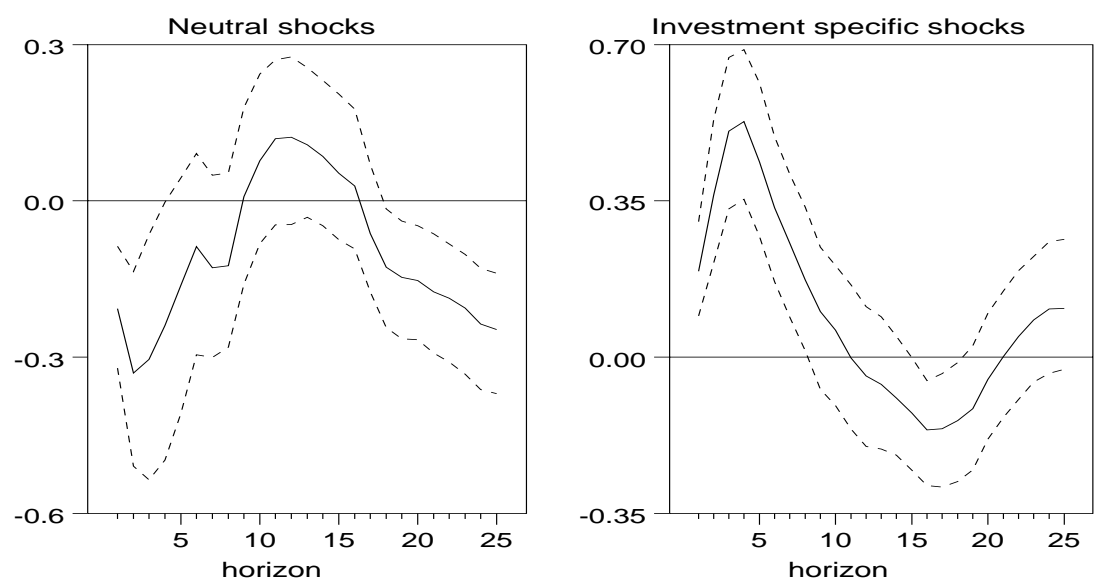

Figure 12: Responses of hours, sign restrictions, dummy specification, 1955-2000 
Figure 12 presents standard error bands for the responses (in this case computed via Monte Carlo integration) together with the median response of per-capita hours to the two shocks. The qualitative pattern of the responses is unchanged: hours fall for 4 quarters in response to a neutral shock (although less persistently so); increase in response to an investment specific shock and display a hump shaped pattern. Perhaps unsurprisingly, it takes much longer for the responses to settle to their long run equilibrium with this specification.

The evidence presented in figure 12 is interesting also from a different perspective. It is often claimed that hours worked could fall after a neutral shock even in a relatively standard RBC model if the income effect of the shock is sufficiently strong (see e.g. Francis and Ramey (2005)). Clearly, a permanent shock has all the characteristics to generate strong income effects. However, for a transitory neutral shock like the one extracted with sign restrictions (all responses eventually converge to zero), the income effect is likely to be much smaller. Still, hours fall. Therefore, a strong income effect is unlikely to be the mechanism which make hours fall in response to neutral shocks

In sum, if one takes the view that low frequency movements in per-capita hours can be characterized with time varying intercepts, and that these movements are nearly orthogonal to the (stationary) short run dynamics of the series, all other important specification choices become irrelevant.

\section{$5 \quad$ How do technology shocks look like?}

Technology shocks are often hard to interpret and they are even more so when they are characterized as unit root processes - at each point in time the probability of a technological regress is non-negligible even if a positive drift is allowed. We have shown that the shocks we have extracted are less than the usual black-box disturbances, as they do not correlate with variables potentially omitted from the specification and they do not stand-in for other sources of structural disturbances. Nevertheless, to be able to understand the transmission pattern they induce, it is necessary to study their properties in more details.

The row panel of figure 13 presents plots of the (smoothed) estimated technology shocks together with NBER recession episodes. Three stark features are evident. First, our neutral shock has time series characteristics which match pretty well NBER phases. In particular, the series displays throughs which are typically coincident with start of NBER recessions. Second, the pattern of ups and downs in shocks to the price of investment only partially coincides with standard NBER classifications and they show somewhat higher frequency movements. Third, if one excludes the 1975 episode, the volatility of the two shock series is comparable. 

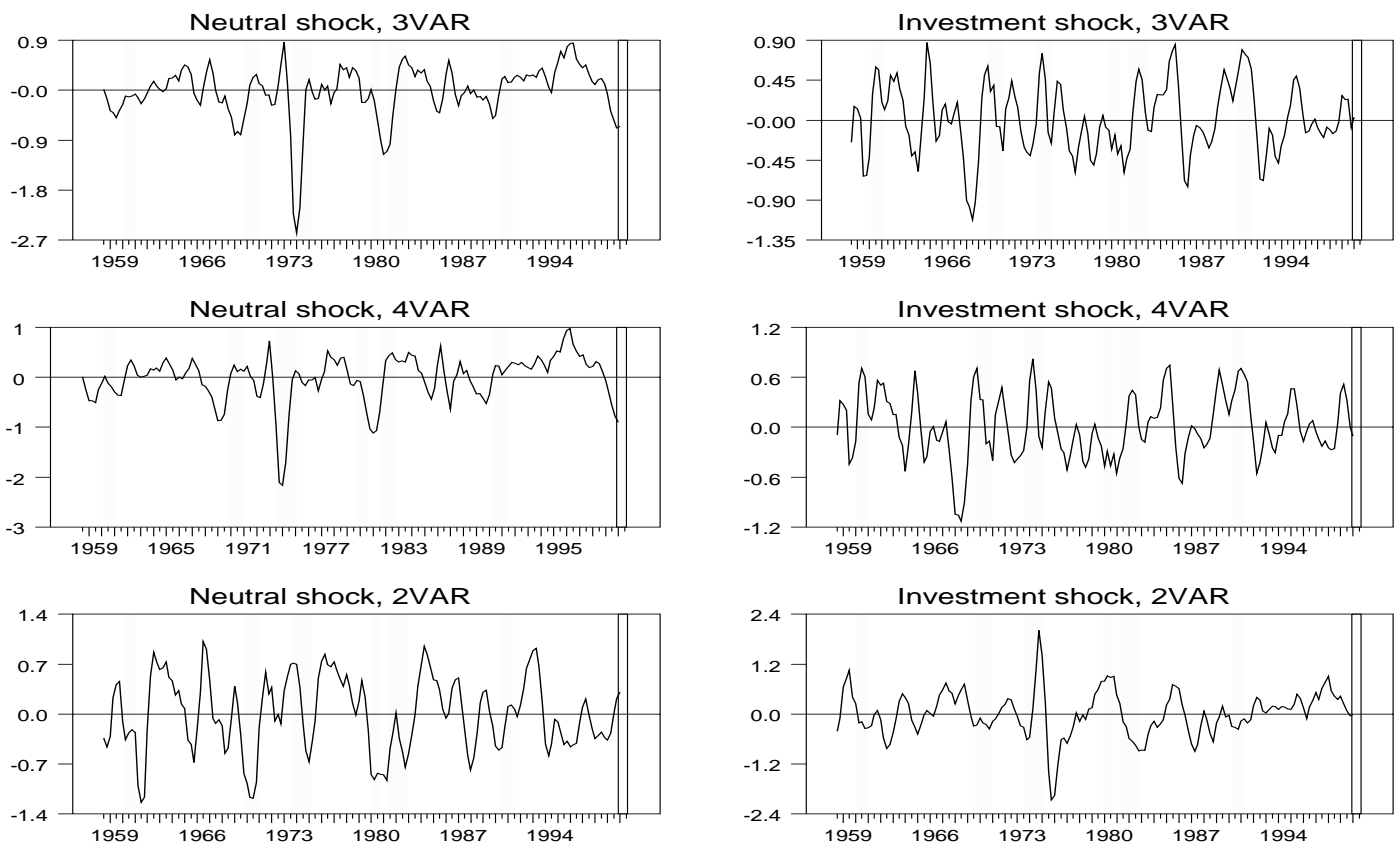

Figure 13: Technology shocks

Since the neutral shock has two deep throughs in 1975 and 1982 and, on average, hours fall in response to neutral shocks, one may be lead to conclude that the two major post WWII recessions were periods where hours worked boomed! Such a conclusion is incorrect since as figure 1 shows, hours fall in these recessions. To assess the role of the two technology shocks in shaping hours fluctuations in specific episodes we present in figure 14 an historical decomposition. Each panel of the figure reports the actual series and the counterfactual series that would have been generated since 1974:1 had only neutral or investment specific shocks being present. Three features are evident. First, the effect of the two shocks on hours worked depends on time and on the state of the economy. Second, in agreement with figure 5 neutral shocks generate minor fluctuations in hours, except for the late 1990s. In particular, they generate no fluctuations in the 1975 recession and only a little fall in the 1982 recession. On the contrary, it is at times when hours peak that neutral shocks induce opposite movements in the counterfactual hour series. Third, investment specific shocks contribute to the fall in hours in the 1975 and 1982 recessions, but a large portion of hours fluctuations in all major historical episodes is left unexplained.

Figure 14 also gives us a clear indication of what the two technology shocks 
we have extracted are. In fact, the counterfactual price of investment series that investment specific shocks generate is practically identical to the observed price of investment series while the counterfactual labor productivity series that neutral shocks generate is practically identical to the observed labor productivity series. The fact that each shock loads only on one variable both in the short and in the long run is consistent with results of section 4 (the location of the identification restrictions does not matter, the lag length of the VAR is unimportant, there are little changes if the unit of measurement change) and suggest that the two technology shocks are simply univariate shocks to the growth rate of relative price of investment and labor productivity. How do these shocks relate to those extracted from standard accounting exercises, which are often used as driving forces in calibrated models ?
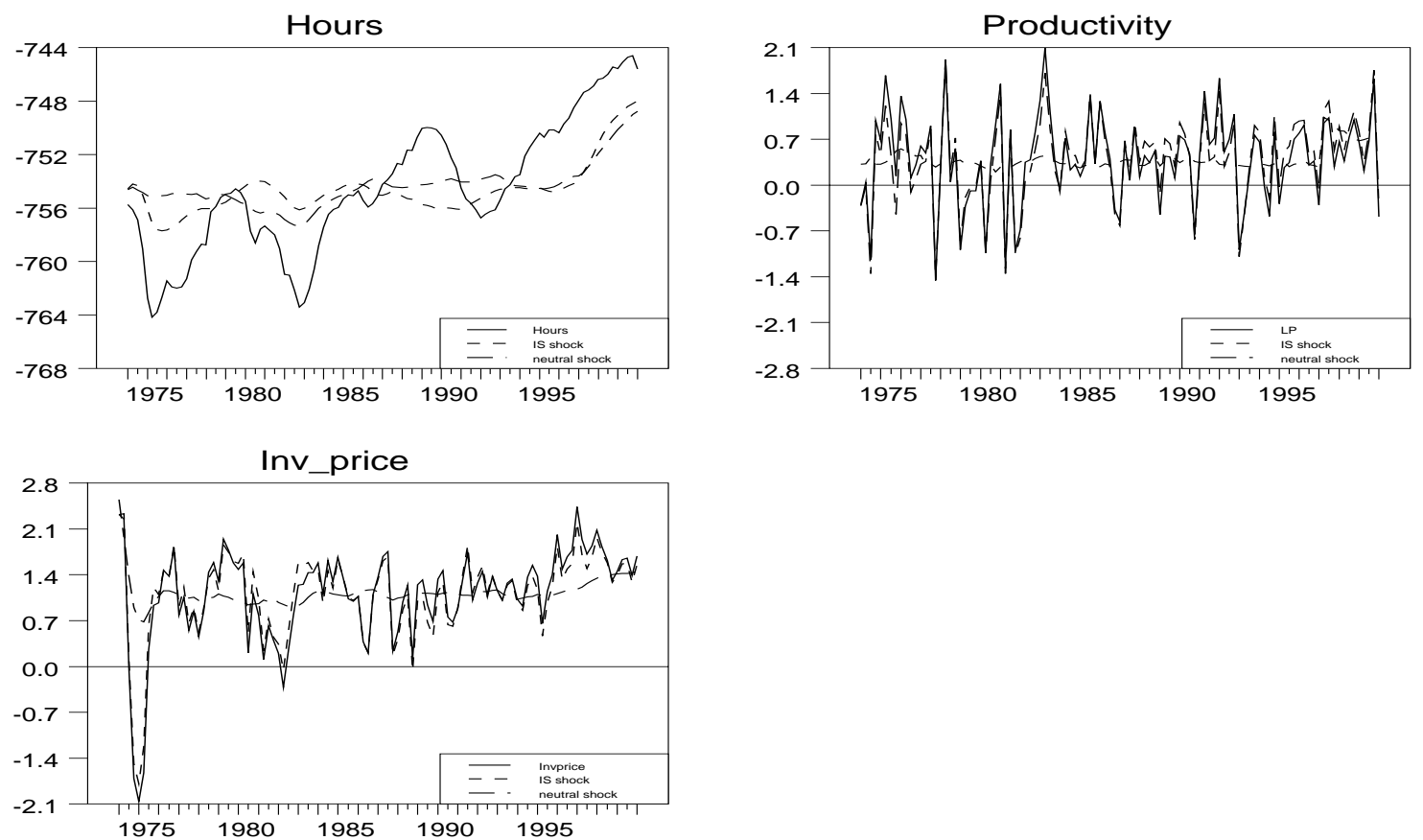

Figure 14: Historical decomposition

We construct Solow residuals shocks, using a Cobb-Douglas production function, adjusting for capacity utilization, and standard estimates of the labor share. Using the definition of labor productivity and the production function, we have that $\frac{y_{t}}{n_{t}}=$ $\left(\frac{u_{t} k_{t}}{n_{t}}\right)^{\alpha} A_{t}$, where $A_{t}$ measures total factor productivity (TFP), $N_{t}$ is private nonfarm 
business sector hours, $u_{t}$ is capacity utilization, and $k_{t}$ are capital services (both of which are obtained from the US Bureau of Labor Statistics). In the upper left corner of figure 15 we plot neutral and TFP shocks obtained differencing the estimated TFP series. It is clear that the correlation of the two series is low (the maximum value occurs contemporaneously and it is only 0.19), that innovations in the estimated TFP displays higher volatility ( 0.79 vs 0.53$)$, that the majority of this volatility is concentrated in the high frequencies of the spectrum, and that TFP shocks are positive at some NBER recession dates. Similar conclusions are obtained if we sample annually our neutral shocks and compare them with the aggregate technology shocks of Basu et al. (2005): the contemporaneous correlation is somewhat lower (0.10) but the ranking of volatilities is unchanged. Hence, if displaying the right sign in major recessions and being coincident and in phase with the NBER indicator is a plus, our neutral shocks have better features than standard TFP shocks.
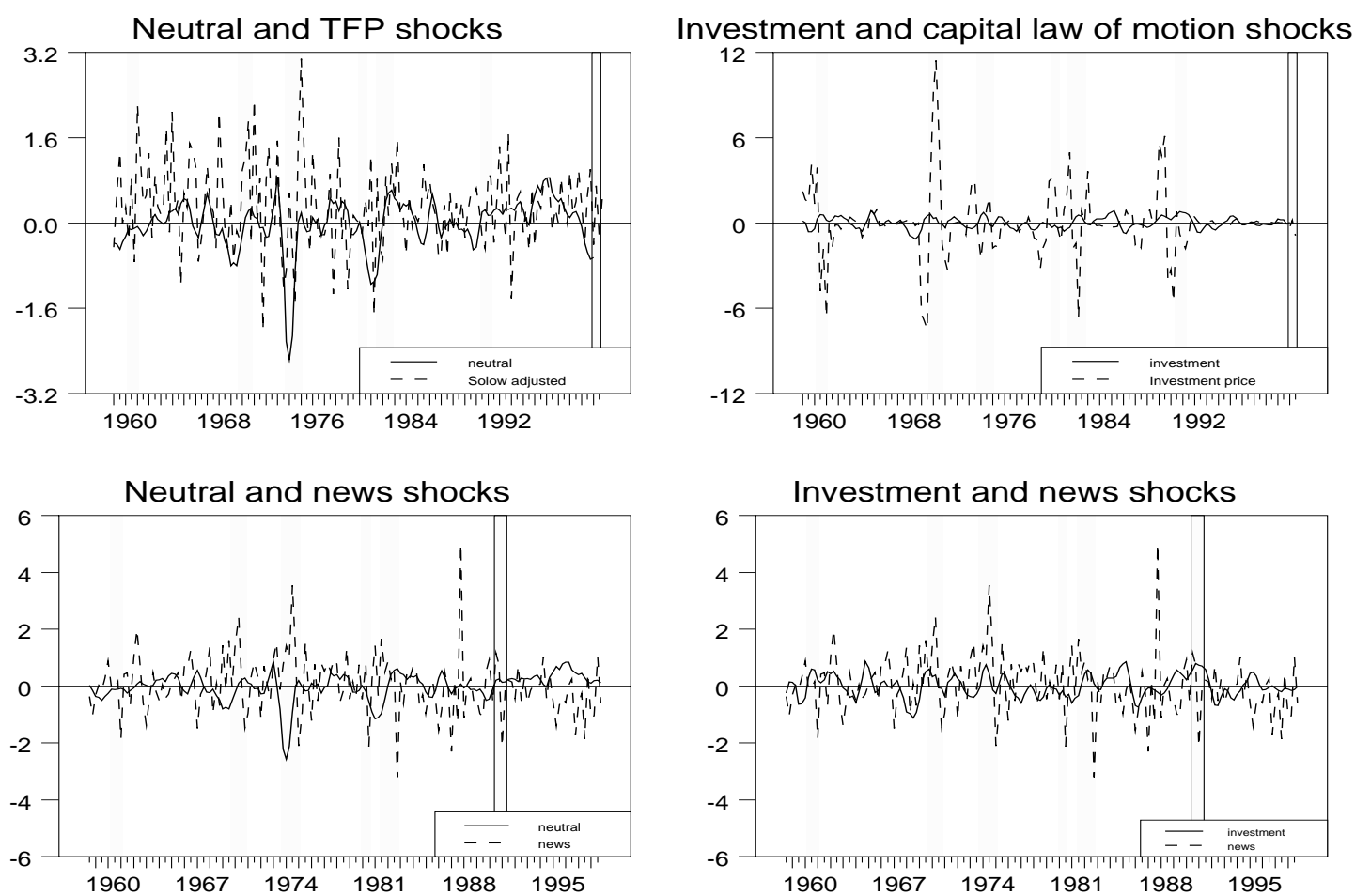

Figure 15: Technology shocks and other shocks

To compare our price investment shock series with an accounting series for disturbances to the price of investment, we used $k_{t+1}=(1-\delta) k_{t}+v_{t} i_{t}$, where $v_{t}$ is 
the inverse of the price of investment, quarterly measures of the capital stock and of the available investment series and differenced the resulting estimate. The upper right corner of figure 15 plots the two series. As it was the case with the neutral shocks, the volatility of the accounting series is much higher than the volatility of our estimated price of investment shock series (2.31 vs 0.40 ). The two series are positively correlated at leads and lags (maximum effect 0.3 at lag 4 ), but differ in the last three NBER recessions.

Beaudry and Portier (2005) have shown that there is a surprising and almost perfect correlation between neutral technology shocks identified with long run restrictions in a bivariate model with TFP and stock prices and what they call "news" shocks, i.e. shocks which do not generate any contemporaneous effects on TFP, but instantaneously affect stock prices. Are our two technological disturbances related to news shocks? We graphically show our two technology shocks and the news shock of Beaudry and Portier in the bottom panels of figure 15. It is clear that the correlation between the two series is far from perfect and, if anything, it looks as if that they are moving in opposite direction, especially at NBER recession dates. For example, in the 1975 recession, news shocks are positive, while both our neutral and investment specific shocks are negative and, even looking forward, news shocks do not capture the dynamics of our two technological shocks. In fact, the regression line between neutral and news shocks has a slope equal to -0.12 ( $t$-stat=-3.03) and the slope does not change magnitude if we lag the news shock series up to 16 quarters. The slope between investment specific shocks and news shocks is -0.11 ( $\mathrm{t}$-stat $=$ -3.15) and its magnitude falls if we lag the news shock series up to 16 quarters.

To confirm that our technology shocks have no relationships with news shocks we perform two additional exercises. First, we examine if adding stock prices to our three variable system changes the informational content of our technology shocks. If news shocks are capturing technology shocks, the time series properties of our two structural disturbances should change if stock prices are added to the system. As shown in the middle row of figure 13, adding stock prices to the system hardly changes the main features of our technological disturbances. Second, we run a trivariate system with stock prices, labor productivity and the price of investment and two bivariate systems with stock prices and either labor productivity or the price of investment and compare them with those obtained in our benchmark VAR. If news shocks are proxying for a number of factors not necessarily related to productivity we should see the time series properties of our technology shocks to vary as we change the information set in the VAR. Indeed, the time series properties of our technology shocks change with the information set and they become completely different in bivariate systems (see bottom row of figure 13. Hence, news shocks correlate with technology shocks only when the conditioning set used in the VAR is limited to a measure of productivity (or the price of investment) and stock prices. 

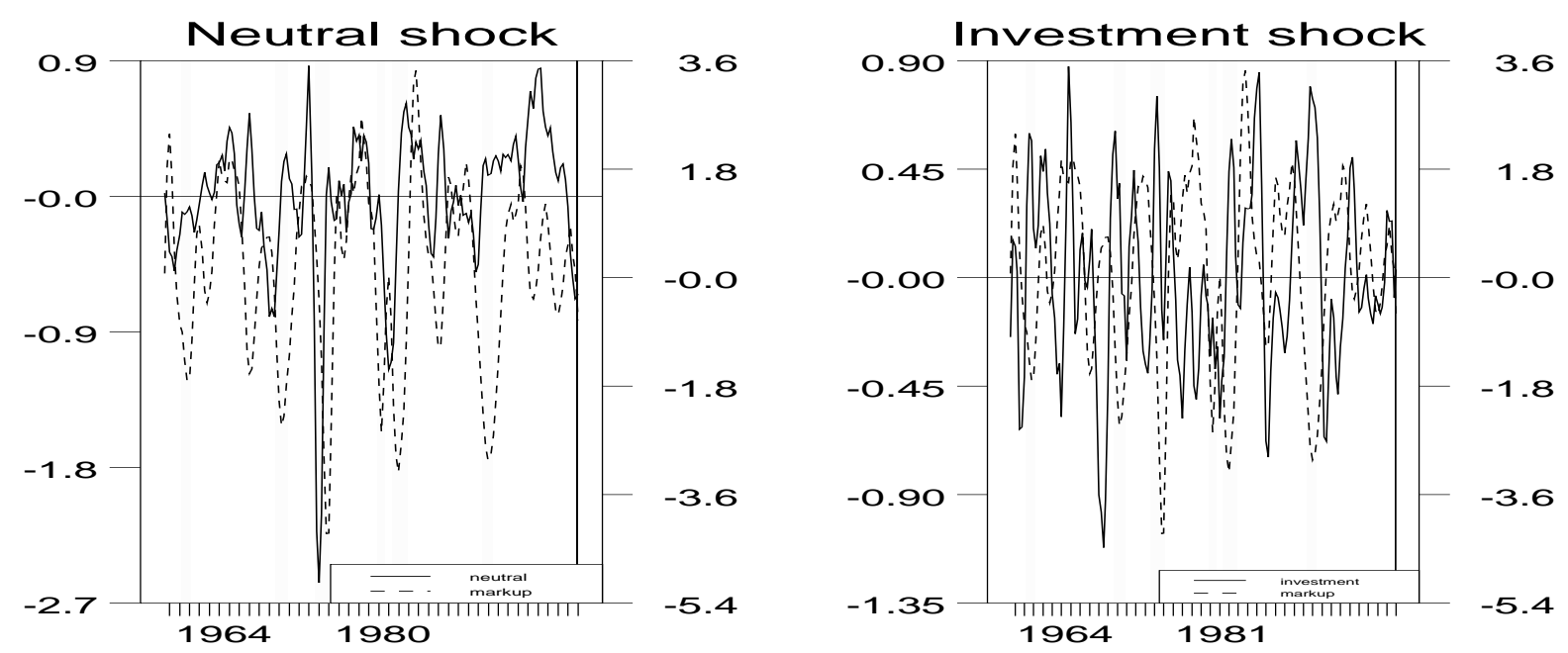

Figure 16: Technology shocks and markup shocks

Comin and Gertler (2006) have recently provided a simple model to jointly explain the short and medium term behavior of total factor productivity, R\&D and the relative price of investment. In their model total factor productivity and the relative price of investment are endogenous and depend on wage markup shocks. It is therefore worth examining whether the two technology shocks we have extracted correlate with markup shocks. We follow Gali et. al (2002) and define the wage markup as the difference between the real wage and household marginal rate of substitution. We assume a utility function of the form $\log c_{t}+\frac{N_{t}^{1+\xi}}{1+x i}$, and use for consumption real per-capita consumption of durable and services, computed using the consumer price index for durable and services, for the real wage, the total real hourly wage compensation and for hours, and for hours per-capita hours in the non-farm business sector. We experimented with various $\xi$ but the results are insensitive to values within the range $[0,6]$. Shocks to the markup are computed regressing the resulting series on one lag. Figure 16 plots the dynamics of our two technology shocks with the resulting markup shocks. Although there are times when neutral shocks and markup shocks are in phase, the contemporaneous correlation between the two is low (0.12). Interestingly, markup shocks are correlated with lags of our technology shocks (maximum at lag 3 of 0.62 ), suggesting the possibility that it is markup shocks that react to neutral shocks not the other way around. The correlation with investment specific shocks is, in general, negative, it is only -0.19 contemporaneously and peaks at two lags of the investment specific shocks $(-0.32)$. 
Hence, our technology shocks do not capture markup shocks either.
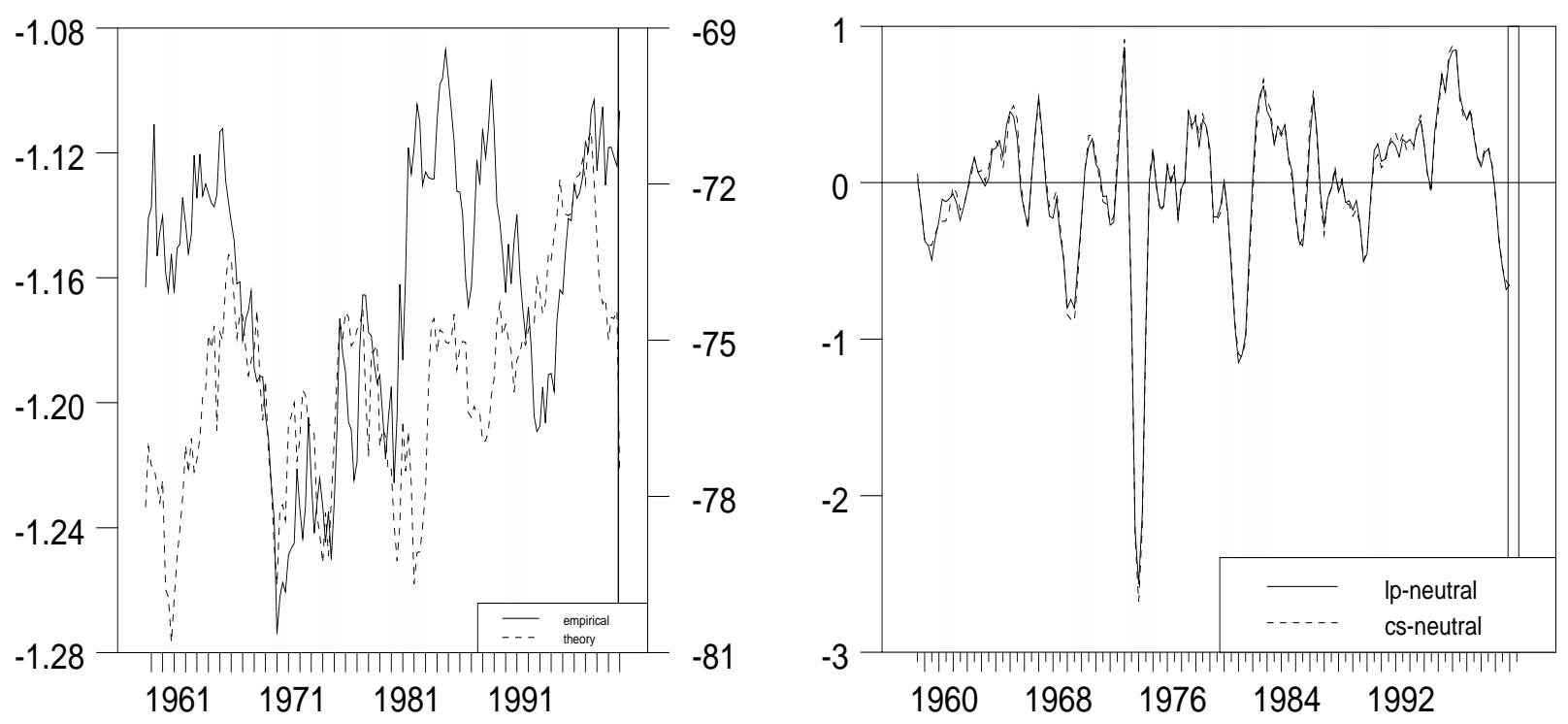

Figure 17: Empirical and theoretical capital shares and neutral shocks.

Finally, we examine the relationship between neutral shocks and the capital share in the economy. Blanchard (1997) has argued that the cyclical behavior of the capital share is of independent interest and that its dynamics could help us to distinguish various theories of the business cycle. In theory, the capital share is equal to one minus the labor share and the labor share in logs is equal to the real wage $\left(w p_{t}\right)$ minus labor productivity $\left(L P_{t}\right)$. Hence, the $\log$ of the capital share $C S_{t}$ is approximately equal to $C S_{t}=L P_{t}-w p_{t}$. We empirically construct capital share from NIPA tables using corporate profits, net interest, rental income and consumption of fixed capital in the numerator and GNP minus proprietor income, net taxes on production and income and the difference between net national product and national income in the denominator. We plot estimates of the capital share in the first panel of figure 17 ("empirical") together with the theoretical measure. While the two series shares the same cyclical behavior in major historical episodes, they are giving a somewhat different picture for the last few years of the sample. Would neutral shocks extracted using capital share rather than labor productivity in the system be different? We plot in the second panel of figure 17 the shocks extracted in the two systems. It is clear that the two series are almost identical, suggesting that shocks that have permanent effects on labor productivity leave real wages unchanged in the long run.

To sum up, neutral shocks have a marked cyclical pattern but, in general, little to do with hours fluctuations except in the late 1990s. The negative hours response 
they induce appears to be due non-recessionary episodes. Investment specific shocks do not display strong cyclical movements, in particular in the latter part of the sample, but they induce movements in hours in the direction one would expect, especially at recession times. The technology shocks one would extract from a bivariate system, TFP data and standard approaches are substantially different from the shocks we have obtained and we find no evidence that our shocks are related to news shocks. Interestingly the shocks we recover are considerably different from accounting shocks, typically used in calibration exercises. It is also clear that a large portion of the fluctuations in hours (and output) are left unexplained, both on average and in specific historical episodes. Hence, what account for these variations?

The residual shock of our system is likely to be difficult to interpret since it captures all the sources of stationary disturbances and the effects of all omitted stationary variables. Nevertheless, a brief analysis of its features may shed light on its nature. It turns out that such a shock is negatively and significantly correlated with the news shock contemporaneously (estimate is -0.03 and t-stat -2.47 ) and that the maximum correlation is with news shocks is lagged 7 quarters (estimate is 0.20 ). We also find that it is somewhat correlated with oil shocks (maximum correlation is 0.17 with 7 leads of oil shocks) and with FFR innovations (maximum correlation is 0.16 with 2 lags of FFR shocks). However, it appears to be unrelated to variables like inflation, the consumption to output or the investment to output ratios which may capture demand driven fluctuations. We also find that the shock is, unsurprisingly, quite cyclical; that it displays throughs at major NBER recessions and that induces positive hours and output responses. Hence, it looks as if it is a disturbance whose origin is in labor markets and it is orthogonal to demand driven fluctuations in goods markets.

\section{Interpretation of the results and conclusions}

This paper has produced a numbrr of interesting and robust facts regarding the relationship between technology shocks and hours worked and technology and other disturbances which we believe are usewufl for theorists engaged i nconstructing realistic models of the business cycle. In particular, we find that, once low frequency movments in hours are taken into account in any reasonable way:

- Per capita hours fall in reasponse to neutral shocks and increase in response to invetsment specific shocks.

- Neutral shocks explain little of per-capita hours fluctuations and a much larger portion of output fluctuations, while the opposite is true for invetsment specific shocks. 
- The negative response of per-capita hours to neutral shocks primarily occurs at non-recessioanry times.

- That the results are robust to a number of modifications in the empirical specification of the model.

Regarding the nature of teh technology shocks we recoved we find that:

- Neutral shocks are more cyclical than invetsment specific shocks and display upturns and downturns which match the NBER classification.

- Both technology shocks are uncorrelated with potentially omitted variables and do not stand-in for other sources of shocks.

- The technology shocks we uncover are uncorrelated with news shocks, technology shocks extracted with accounting exercises or markup shocks.

- Shocks other than technology disturbances are more important in explaining the dynamics of per-capita horus since the mid-1950s.

Will will not fall int othe trap of trying to directly relate our finding to theories of the business cycle without explicitly simulating these models and running VARs similar to those we have run on similar sample sizes. Nevertheless, we would like to point out that our results seems hard to reconcile with standard models, both of flexible price and sticky price orientations. In particular, models with a standard production function and preferences where the income effect on labor supply plays a small role, will have hard time to generate different signs and different magnitudes in hours in response to neutral and investment specific shocks. They will also find it hard to reproduce the relative size of hours (and output) fluctuations explained by the two technology shocks we found in the data. Finally, neither of these types of model has built-in mechanisms so that per-capita hours fall in response to neutral shocks primarily at non-recessioanry times.

There are many dimensions along which our work could be extended or qualified. Canova et. al. (2006) we have studied how other labor market margins react to technology shocks. Extending these studies, either explicitly allowing time variations in both the intercept and the slope of the model (as in Gambetti (2005)), or across countries, can help to provide a more complete picture of the dynamics induced by technology shocks in labor markets and suggest ways to accoutn for them. 


\section{References}

[1] Altig, D. Christiano, J. Eichenbaum, M. and Linde, J. (2005), "Firm-Specific Capital, Nominal Rigidities and the Business Cycle", NBER Working Paper 11034.

[2] Basu, S., Fernald, J, and Kimball, M. (2005) "Are technology improvements contractionary?", forthcoming, American Economic Review

[3] Beaudry, P. and Portier, F. (2005), " Stock prices, news and economic fluctuations, forthcoming, American Economic Review

[4] Blanchard, O (1997) "The Medium Run",Brookings Papers on Economic Activity, 2, 89-158.

[5] Canova, F., Lopez Salido, D. and Michelacci, C. (2006) "The labor market responses of technology shocks", mansucript.

[6] Chari, V.V., Kehoe, P. and McGrattan, E. (2005) A critique of SVAR using Real Business Cycle theory, Fed of Minneapolis, working paper 631.

[7] Christiano, L, Eichenbaum, M. and Vigfusson, R.(2003) "What happens after a technology shock", Northwestern university, http://www.faculty.econ.northwestern.edu/faculty/christiano/research.htm.

[8] Comin, D. and Gertler, M. (2005) Medium Term Business Cycles, American Economic Review, 96, 523-551.

[9] Dedola, L. an Neri, S. (2004) What does a technology shock do? A VAR Analysis with model-based sign restrictions, forthcoming, Journal of Monetary Economics.

[10] Erceg, C., Guerrieri, L. and Gust, C. (2005) "Can Long Run Restrictions Identify technology shocks", forthcoming, Journal of the European Economic Association.

[11] Evans, C. (1992) "Productivity Shocks and Real Business Cycles", Journal of Monetary Economics, 29, 191-208.

[12] Faust, J. and Leeper, E. (1997) "Do Long Run Restrictions give reliable Results", Journal of Business and Economic Statistics, 15, 343-353.

[13] Fernald, J. (2004), "Trend Breaks, Long Run Restrictions, and the Contractionary Effects of Technology Shocks", Federal Reserve Bank of San Francisco, working paper 2005-21.. 
[14] Fisher, J. (2006), "Technology Shocks Matter", 114, 413-451.

[15] Francis, N. and Ramey, V. (2005), "Is the Technology-Driven Real Business Cycle Hypothesis Dead? Shocks and Aggregate Fluctuations Revisited", Journal of Monetary Economics, 52, 1379-1399.

[16] Francis, N. and Ramey, V. (2006), "Measures of per-capita hours and their implications for the technology-hours debate", University of North Carolina, manuscript.

[17] Galí, J. (1999), "Technology, Employment, and the Business Cycle: Do Technology Shocks Explain Aggregate Fluctuations?", American Economic Review, 89, 249-271.

[18] Galí, J. (2005), "Trends in hours, Balanced Growth, and the Role of Technology in the Business Cycle ", Federal Reserve of St. Louis Review, July-August, 459486.

[19] Galí, J., Gertler, M., and Lopez Salido D. (2002) "Markups, Gaps and the Welfare Costs of Business Cycles", NBER working paper 8850.

[20] Galí, J. and Rabanal, P., (2004), "Technology Shocks and Aggregate Fluctuations: How Well Does the RBC Model Fit Postwar U.S. Data?", NBER Macroeconomics Annual, 225-288.

[21] Gambetti, L. (2005) Technology shocks and the response of hours worked: time varying dynamics matter, http:// www.econ.upf.es/gambetti.

[22] Giordani, P. (2004) An alternative explanation of the price puzzle, Journal of Monetary Economics, 51, 1271-1296.

[23] Greenwood, J. and M. Yorokoglu (1997), "1974”, Carnegie-Rochester Conference Series on Public Policy 46, 49-95.

[24] Kilian, L. (1998) "Finite sample properties of bootstrap and percentile tbootstrap confidence interval for Impulse responses", Review of Economics and Statistics, 81, 652-660.

[25] Fernandez-Villaverde, J. Rubio-Ramirez, J., and Sargent, T. (2005), "The ABC (and D) for understanding VARs", Federal Reserve of Atlanta, working paper 2005-9.

[26] Uhlig, H. (2004), "Do technology shocks lead to a fall in total hours worked" Journal of the European Economic Association, 2, 361-371. 
[27] Vigfusson, R. (2004) The delayed response to technology shock: a flexible price explanation, Federal Reserve Board, International Finance discussion paper 810. 